\title{
MEANS OF IMPLICIT TEMPORAL LOCALIZATION OF A FUTURE ACTION: A VARIANT OF CLASSIFICATION ${ }^{1}$
}

\author{
Olga V. Larina \\ Moscow State Institute of International Relations (MGIMO), Moscow, Russian Federation
}

\begin{abstract}
The research investigates the phenomenon of implicitness in the English language (in accordance with the understanding of the concept in contemporary linguistics) and is dedicated to the functional-semantic analysis of different means of implicitly locating an action in the future in English discourse (based on the British variant of the English language). In the article we analyze one work of fiction, on the basis of which we set out to explore discourse units pertaining to different levels (primarily utterance and supra-phrasal unit); within this corpus temporal characteristics of separate language forms and structures are hence established through componential analysis. Suprasegmental analysis is employed to examine implicit semantics of the means of temporal location of a future action from the perspective of adjacent and distant links between the elements that are related to each other formally and associatively. In the research we also endeavor to propose a level classification of linguistic devices that implicitly render the sense of temporality. As it is shown in the article, all implicit means fall within three categories: morphologic-syntactic, syntactic-semantic and contextual. The analysis of different implicit temporal structures is conducted regardless of the modal component of the meaning of future verb forms, a consideration which may serve as a starting point of further research.
\end{abstract}

Key words: implication, implicit means, temporal localization, future tense, classification.

УДК 81 '36

ББК 81.052
Дата поступления статьи: 11.10 .2016 Дата принятия статьи: 15.11.2016

\section{СРЕДСТВА ИМПЛИЦИТНОЙ ТЕМПОРАЛЬНОЙ ЛОКАЛИЗАЦИИ БУДУЩЕГО ДЕЙСТВИЯ: ВОЗМОЖНАЯ КЛАССИФИКАЦИЯ ${ }^{1}$}

\author{
Ольга Всеволодовна Ларина \\ Московский государственный институт международных отношений (Университет), \\ г. Москва, Российская Федерация
}

\begin{abstract}
Аннотация. Работа посвящена рассмотрению явления имплицитности и функционально-семантическому анализу имплицитных средств темпоральной локализации действия в будущем в англоязычном дискурсе (на материале британского варианта английского языка). Для анализа взято одно произведение художественной литературы (роман С. Фрая «The Liar»), в нем исследованы разноуровневые единицы дискурса (высказывание и сверхфразовое единство), в рамках которых методом компонентного анализа определены временные характеристики отдельных языковых форм и структур. Суперсегментный анализ использован в тех случаях, когда имплицитные средства выражения действия в будущем рассматриваются в аспекте смежных и дистантных связей с элементами, ассоциативно или формально соотносимыми. В работе предложена уровневая классификация вербальных средств, имплицитно передающих значение тем음 поральности. Средства имплицитной передачи времени действия в будущем разделены на три группы: ㄱ. морфолого-синтаксические, синтактико-семантические и контекстуальные. Анализ разноуровневых средств ضં имплицитной передачи темпоральной информации в будущем проведен без учета модальных компонентов значения видовременных форм глаголов в будущем времени. В связи с этим намечены перспективы проводимого исследования.

Ключевые слова: импликация, имплицитное средство, темпоральная локализация, будущее время, классификация.
\end{abstract}




\section{1}

Что же такое время? Если никто меня об этом не спрашивает, я знаю, что такое время; если бы я хотел объяснить спрашивающему - нет, не знаю.

Августин Аврелий

Признание значимости изучения двух важнейших функций языка - когнитивной и коммуникативной - привело к тому, что особое внимание в языкознании стало уделяться возможностям передавать средствами естественного языка потенциально заложенные, но не эксплицированные в высказывании смыслы, а также механизмам их интерпретации. В связи с этим ученые вновь и вновь обращаются к феномену имплицитности в языке, благодаря которому естественный язык, представляющий собой конечную систему знаков, может передавать неограниченное разнообразие смыслов, рожденных человеческим мышлением. Тот факт, что время, наряду с пространством, является важнейшей онтологической категорией, определяет непреходящий интерес лингвистов к разнообразным способам его актуализации в языке, в частности к имплицитнылм способам выражения этой категории.

«Время, - пишет Н.Д. Арутюнова, - восприятию недоступно, и его модели изменчивы. Время описывается в метафорических терминах, легко допускающих противоречия» [1, c. 695]. Тем менее доступно восприятию будущее, которое мы можем планировать, пытаться предугадывать, о котором мы можем строить предположения, но знать которое нам не дано. «По отношению к будущему времени, считает О. Есперсен, - мы не можем высказывать никаких утверждений, кроме предположений и догадок» $[3$, с. 310$]$. Именно с этим связаны трудности, с которыми сталкивается каждый исследователь, описывающий то, каким образом концепт «будущее» существует в языковом преломлении. Мнения большинства лингвистов сводятся к тому, что будущее в языке не существует в отрыве от модальности, то есть в каждом высказывании о предстоящих событиях содержится, помимо темпорального значения, еще и их субъективная оценка говорящим. В связи с этим в современной грамма- тической семантике будущее время, наряду со значениями желательности, необходимости, возможности, относят к контекстам «снятой утвердительности» [5, с. 94-102; 9, с. 37-45]. В отношении английского языка многие исследователи склонны считать, что будущего времени как отдельной грамматической парадигмы в нем нет вовсе, а есть только набор модальных конструкций для выражения будущего действия (см.: [11-13; 15; и др.]).

В данной статье мы предлагаем возможную классификацию имплищитных ${ }^{2}$ средств темпоральной локализации ${ }^{3}$ действия в будущем. Для решения этой задачи мы, вслед за целым рядом исследователей (см., например: $[10 ; 14])$, принимаем положение о существовании футурума как отдельного грамматического времени глагола. При этом отметим, что проблема модальности в статье не затрагивается, хотя автор вполне отдает себе отчет в том, что дальнейшее исследование имплицитного выражения семантики будущего невозможно без анализа модальных значений имплицитных футуральных конструкций.

Для того чтобы предложить классификацию имплицитных средств темпоральной локализации действия в будущем, необходимо определить набор тех конструкций, которые мы будем принимать за эксплицитные формы выражения будущего времени. Для английского языка характерен интенсивный способ временной локализации второй степени интенсивности (подробнее см.: [6]), действие при этом локализуется сразу двумя способами. Эксплицитным средством темпоральной локализации морфологического / морфолого-семантического характера является видовременная глагольная форма.

Споры относительно количества и состава эксплицитных средств футуральной темпоральной локализации ведутся до сих пор. Лингвисты традиционно включают в список все конструкции со вспомогательным глаголом will, относящие действие к сфере будущего, времена Present Continuous, Present Simple, выражения be going, be to, to be about to. Однако некоторые исследователи предлагают более развернутую классификацию. Так, список средств выражения действия в будущем, составленный Е.Е. Селивановой, состоит из более чем ста пунктов [7]. 


\section{МАТЕРИАЛЫ И СООБЩЕНИЯ}

Принимая во внимание различия во мнениях ученых, при определении имплицитных средств выражения будущего времени наличие эксплицитных форм мы учитываем, но не рассматриваем подробно, поскольку они выражают только отнесенность действия к определенной временной сфере.

Источником языкового материала послужил роман Стивена Фрая «The Liar», из которого методом сплошной выборки были извлечены контексты, содержащие средства имплицитного выражения будущего времени. На основе их анализа предложена следующая уровневая классификация.

\section{2}

Все имплицитные средства временной локализации действия в будущем (так же, как и в прошлом [4]), можно разделить на три группы: морфолого-синтаксические средства, синтактико-семантические средства, контекстуальные средства.

Морфолого-синтаксические средства. К этой группе принадлежат такие предикативные конструкции, временную характеристику которых можно определить с учетом морфологических особенностей видовременных глагольных форм, входящих в их состав. Сюда относится ряд средств имплицитной темпоральной локализации действия.

- Порядок следования личных форм глаголов в будущем времени (обычно в Future Simple) (последовательность действий).

Например: "We'll take a look at the pitch," he told Hooper, the captain, "and we'll decide then" (р. 290). Данное средство имплицирования временных отношений является отражением объективной реальности, поскольку при отсутствии других темпоральных локализаторов действие, стоящее в последовательности глагольных форм на первом месте, воспринимается как хронологически предшествующее действиям, следующим за ним в предложении.

- «Презенс запланированного будущего» - формы настоящего времени, описывающие ситуации, еще не имеющие места в момент речи, но их наступление запланировано говорящим.

Запланированная будущая ситуация заранее включается в цепь реальных событий:
"When I've designed it, I simply hang the sheet over the wall, prick the outline onto the wet plaster and get to work as quickly as possible before..." "What wet plaster would that be?" Gary pointed to a blank space of wall. "I thought there. We just rip off the old plasterwork [...], and Bob's your uncle" (p. 78-79).

В данном случае последовательность действий получает как бы двойную временную отнесенность. С одной стороны, все действия, выраженные формами Present Simple, принадлежат к сфере будущего, но, с другой стороны, они локализованы во времени и по отношению друг к другу таким образом, что первое действие в данной цепочке является первым и хронологически. Особую роль для данного вида временной локализации играет использование определенных артиклей. Именно они позволяют в подобных случаях интерпретировать последовательность форм Present Simple как презенс запланированного будущего, в отличие от актуального презенса повторяющегося действия.

По утверждению А.В. Бондарко, для неактуального презенса «семантика настоящего времени не имеет той дейктической направленности, которая отличает формы прошедшего и будущего, и занимает неопределенносрединное положение между этими сферами» [2, c. 22]. Употребление Present Simple в этом значении обусловлено действием механизма транспозиции.

Синтактико-семантические средства. В эту группу входят структуры уровня предложения и сверхфразового единства (СФЕ), в которых непрямое указание на время осуществляется через семантику отдельных входящих в их состав единиц или высказывания в целом.

В таких синтаксических структурах время действия может быть выражено по-разному.

- Указание на время действия посредством указания на место действия.

Например: The Tweed Jacket and the Blue Button-down had just entered the room. "You start at the end, Adrian, and we'll meet in the middle" (p. 3); в данном контексте обстоятельство места указывает еще и на время действия глагола meet [*when we get to the middle]. Приведем еще один пример: This organization 
is proposing to put Christopher through Cambridge. He will read not Pure Maths there, but Engineering (p. 231). Здесь there в равной степени обозначает как место, так и время действия.

Рассмотренное явление уже неоднократно попадало в поле зрения исследователей. Так, С. Деланси в своей работе, посвященной видовременным формам глагола, говорит об имманентной физической неразделимости пространственно-временных измерений [8], этот феномен отражается в языках как некоторое перекрывание в кодировании времени и пространства. Многие ученые считают данное явление языковой универсалией и объясняют его первичностью пространственной перспективы для человеческого восприятия.

- Указание на время действия посредством указания на лицо, производящее действие.

В большинстве таких случаев конструкции с футуральным значением в художественном произведении локализуются во времени через соотнесенность с жизнью определенного персонажа: So now I'm going to wake up every morning for the rest of my life knowing that I'm responsible for someone's suicide (p. 175).

Действие в предложении может быть темпорально локализовано не только через субъект действия, но и через любое другое сопутствующее действию лицо: He's beginning to resent Trotter's posthumous power over him, Adrian thought (р. 177). Выделенное словосочетание указывает на то, что действие, названное глагольной формой, происходит (и будет происходить) после смерти персонажа.

- Указание на время действия посредством указания на любые объекты или обстоятельства, опосредованно выражающие время действия.

Иногда значение времени содержится в слове или словосочетании, с помощью которых осуществляется локализация (first, last beginning, end и т. д.), их использование в предложении дает возможность адресату довольно точно определить время действия ассоциируемого с ними глагола. Например: 'Will you be around for initialing appropriation orders, sir?' (р. 220). Хотя здесь словосочетание initialing appropriation orders вполне однозначно указывает на время действия глагола во второй части высказывания, данный пример иллюстрирует имплицитное выражение будущего времени, поскольку названное словосочетание не является обстоятельством времени в структуре предложения. Подобные случаи соответствуют важнейшему требованию имплицитности: они предполагают некоторые усилия со стороны адресата, которые направлены на получение косвенной темпоральной информации.

Приведем еще один пример имплицитной временной локализации действия через сопутствующие обстоятельства: If you don't mind standing here in the sun I'll come amongst you now with individual notes (р. 137). Здесь упоминание the sun является достаточным для понимания адресатом того, что действие, обозначенное глаголом, произойдет днем.

К этой группе средств выражения имплицитной темпоральной локализации действия относятся такие, необходимым условием правильной интерпретации которых является совпадение сферы фоновых знаний адресанта с фоновыми знаниями адресата. Например: The Evening News is sure to cover it. And tomorrow the nationals. What the hell are we going to do? (p. 204). В данном случае помимо того, что на предполагаемую темпоральную локализацию действия указывает слово evening, адресату также требуются фоновые социокультурные знания особенностей времени выхода газеты «The Evening News».

- Указание на время действия посредством структур с каузальным значением.

Этот способ связан с семантикой контекста - СФЕ или текста. Например: "Oh hell's bells. It'll be all over school". "Of course it won't be," said Adrian. "Tickford won't tell anyone. I certainly won't tell anyone" (p. 174). Действие глагола tell воспринимается адресатом как причина (предлагаемое рассказчиком логическое обоснование) действия, выраженного глаголом $b e$. Установленная причинно-следственная связь помогает определить и временные отношения между формами данных глаголов, поскольку причина всегда предшествует следствию.

Данный способ имплицитной временной локализации представляется более характерным для флективных языков (например, рус- 


\section{МАТЕРИАЛЫ И СООБЩЕНИЯ}

ского), в которых суперсегментные аспекты синтаксических структур (паузы, интонация, выражающиеся на письме с помощью знаков препинания) чаще используются для указания на логический порядок следования частей дискурса с каузальным значением. В английском языке наиболее часто встречается проспективный вид причинно-следственной связи (действие-причина предшествует в синтаксических единицах действию-следствию), который не позволяет четко установить, что именно способствует определению временной принадлежности частей СФЕ: порядок следования видовременных форм или каузальные отношения между ними.

Тем не менее нам представляется, что даже каузальные структуры с проспективной связью следует отнести к имплицитным средствам временной локализации действия. Рассмотрим пример, подтверждающий наше утверждение: And the state will hope that he goes into something productive once he has obtained his degree. He will be incented by money, recruitment drives and the general thrust and tenor of the times (p. 234). Если части приведенной ситуации расположить в обратном порядке, то при восстановлении хронологии их следования мы, скорее всего, будем руководствоваться логикой именно причинно-следственных отношений между ними.

- Указание на время действия посредством свернутых (компрессивных) структур.

Например: The only thought that will give me energy to carry on is that someone has a life which would be diminished by my departure from it (p. 155). Здесь существительное пропозитивной семантики thought может быть развернуто в придаточное предложение времени [*when I think that someone has a life... it will give me energy].

- Указание на время действия посредством конструкций с придаточными условия.

Например: Spuds have to grow underground, see. If they poke up through the soil and catch the rays of the sun you'll get photosynthesis and that gives you chlorophyll which'll turn them green (p. 96). В этом контексте условие осуществления действия в главном предложении также косвенным образом указывает на его время, а темпоральные характеристики глагола get имплицируются и через значение словосочетания rays of the sun.

Контекстуальные средства. Указание на темпоральную локализацию предикативных структур можно обнаружить внутри содержащего их сверхфразового единства или за его пределами (широкий контекст, фоновые знания). К подобным способам относятся следующие:

- Сопутствующее действие.

Такой способ позволяет имплицировать время действия через соотнесенность этого действия с другим действием или ситуацией, которые эксплицитно темпорально локализованы в тексте и имеют логическую связь с рассматриваемым действием. Например: Stephen is a chess player. He's coming over here to play in a couple of months. They'll keep him on a long leash I shouldn't wonder (р. 238). В данном случае логично предположить, что действие во втором предложении также произойдет не раньше, чем через два месяца.

- «Анафорический антецедент».

Таким средством являются высказывания, в которых в цепочке глагольных форм действия последующих глаголов воспринимаются как происходящие одновременно с действиями предшествующих на основании разнообразных смысловых связей между ними ${ }^{4}$. В результате действие первой финитной формы глагола в последовательности воспринимается как временной центр, по отношению к которому локализуются все следующие глагольные формы, например: After we've graduated we'll fly to Los Angeles or Amsterdam to get married - you can there, you know. Then we'll set up house in the country. I'll write poetry. Hugo will play the piano and look beautiful (p. 124). В приведенном контексте последние два предложения поясняют, что именно автор подразумевает под действием, выраженным глаголом set up.

- Широкий контекст.

Например: "The court will weep big tears for you, my son. Probation and sympathy". <..> "I mean he won't ever know, will he? I won't have to give evidence against him or anything?" (p. 269). Действие глагола give относится к ранее описанным в произведении событиям, поэтому для определения его темпоральной локализации достаточно вспомнить предыдущий контекст. 


\section{3}

Итак, проведенный анализ позволил установить номенклатуру средств имплицирования будущего действия и предложить их классификацию.

Поскольку темпоральность - это референциальная категория, а учет особенностей временного дейксиса является неотъемлемой частью процесса извлечения имплицитных временных данных, дальнейшее исследование особенностей функционирования имплицитных футуральных конструкций представляется целесообразным проводить в русле референциального анализа, что позволит создать двухэтапную когнитивную модель понимания адресатом имплицитной темпоральной информации.

\section{ПРИМЕЧАНИЯ}

1 Исследование выполнено при финансовой поддержке МГИМО (Университета) в рамках III Конкурса молодых ученых МГИМО (Университета) МИД России 2016 г. (проект «Имплицитность темпоральности в современной художественной литературе»).

2 Под имплицитностью нами понимается категория дискурса, представляющая собой подразумеваемую дополнительную информацию, не имеющую явного (словесно-конструктивного) выражения, но вытекающую из семантики, форм и сочетания компонентов данного высказывания.

3 Термин «темпоральная локализация» понимается нами широко. Любое действие, выраженное личной формой глагола в изъявительном наклонении, интерпретируется как локализованное, то есть занимающее определенное место во временном континууме на темпорально-дейктической оси.

${ }^{4}$ Последующие глаголы могут раскрывать, уточнять или перефразировать смысл первого в последовательности. Однако независимо от характера семантической связи действие первого глагола выступает в качестве антецедента (с точки зрения локализации во времени) для всех следующих глаголов.

\section{СПИСОК ЛИТЕРАТУРЫ}

1. Арутюнова, Н. Д. Язык и мир человека / Н. Д. Арутюнова. - М. : Языки русской культуры, 1999. -896 c.

2. Бондарко, А. В. Теория функциональной грамматики. Темпоральность. Модальность / А. В. Бондарко. - М. : Наука, 1990. - 164 с.
3. Есперсен, О. Философия грамматики / О. Есперсен. - М. : Изд.-во иностр. лит., 1958. - 404 с.

4. Ларина, О. В. Функционирование имплицитных средств темпоральной локализации действия в англоязычном дискурсе : дис. ... канд. филол. наук / Ларина Ольга Всеволодовна. - М., 2009. $232 \mathrm{c}$.

5. Падучева, Е. В. Высказывание и его соотнесенность с действительностью / Е. В. Падучева. М. : Наука, 1985. - 288 с.

6. Резник, И. В. Функционально-семантическое поле темпоральности: логико-семантическая категория и способы ее языкового выражения : дис. ... канд. филол. наук / Резник Ирина Владимировна. - М., 1987. - 187 c.

7. Селиванова, Е. Е. Средства выражения категории футуральности в английском дискурсе : дис. ... канд. филол. наук / Селиванова Елена Евгеньевна. - М., 2003. -289 с.

8. Delancey, S. Aspect, Transitivity and Viewpoint / S. Delancey // Tense - Aspect : Between Semantics and Pragmatics. - Amsterdam : Philadelphia, 1982. - P. 167-184.

9. Haspelmath, M. Indefinite pronouns: Oxford Studies in Typology and Linguistic Theory / M. Haspelmath. - Oxford : Oxford University Press, 1997. -364 p.

10. Hornby, A. S. Oxford Progressive English for Adult Learners / A. S. Hornby. - Oxford : Oxford University Press, 1954. - 204 p.

11. Jespersen, O. Essentials of English Grammar / O. Jespersen. - London : Allen \& Unwin, 1931. $387 \mathrm{p}$.

12. Kruisinga, E. A Handbook of Present-Day English. P. II / E. Kruisinga. - Groningen : P. Noordhoff, 1931. $-508 \mathrm{p}$.

13. Quirk, R. A Comprehensive Grammar of the English Language / R. Quirk. - London : Longman, 1985. $-1779 \mathrm{p}$.

14. Sinclair, J. Collins CoBUILT English Grammar / J. Sinclair. - London : Collins CoBUILT, 1990. - 448 p.

15. Yule, G. Explaining English grammar/G. Yule. Oxford : Oxford University Press, 1998. - 352 p.

\section{ИСТОЧНИКИ}

Fry, S. The Liar / S. Fry. - London : Soho Press, 1994. $-280 \mathrm{p}$.

\section{REFERENCES}

1. Arutyunova N.D. Yazyk i mir cheloveka [Language and Human World]. Moscow, Yazyki russkoy kultury Publ., 1999. 896 p. 


\section{МАТЕРИАЛЫ И СООБЩЕНИЯ}

2. Bondarko A.V. Teoriya funktsionalnoy grammatiki. Temporalnost. Modalnost [The Theory of Functional Grammar. Temporality. Modality.]. Moscow, Nauka Publ., 1990. 164 p.

3. Espersen O. Filosofiya grammatiki [The Philosophy of Grammar]. Moscow, Izd-vo Inost. Lit., $1958.404 \mathrm{p}$.

4. Larina O.V. Funktsionirovanie implitsitnykh sredstv temporalnoy lokalizatsii deystviya $v$ angloyazychnom diskurse: dis. ... kand. filol. nauk [The Functioning of Implicit Means of Temporal Location of an Action in English Discourse. Cand. philol. sci. diss.]. Moscow, 2009. 232 p.

5. Paducheva E.V. Vyskazyvanie $i$ ego sootnesennost $s$ deystvitelnostyu [Utterance and its Correlation with Reality]. Moscow, Nauka Publ., 1985. $288 \mathrm{p}$.

6. Reznik I.V. Funktsionalno-semanticheskoe pole temporalnosti: logiko-semanticheskaya kategoriya $i$ sposoby ee yazykovogo vyrazheniya: dis. ... kand. filol. nauk [TheFunctional-Semantic Field of Temporality: LogicSemantic Category and the Means of Its Linguistic Expression. Cand. philol. sci. diss.]. Moscow, 1987. 187 p.

7. Selivanova E.E. Sredstva vyrazheniya kategorii futuralnosti $v$ angliyskom diskurse: dis. ... kand. filol. nauk [The Means of Expressing the
Category of Futurality in English Discourse. Cand. philol. sci. diss.]. Moscow, 2003. 289 p.

8. Delancey S. Aspect, Transitivity and Viewpoint. Tense - Aspect: Between Semantics and Pragmatics. Amsterdam, Philadelphia, 1982, pp. 167-184.

9. Haspelmath M. Indefinite pronouns: Oxford Studies in Typology and Linguistic Theory. Oxford, Oxford University Press, 1997. 364 p.

10. Hornby A.S. Oxford Progressive English for Adult Learners. Oxford, Oxford University Press, 1954. $204 \mathrm{p}$.

11. Jespersen O. Essentials of English Grammar. London, Allen \& Unwin, $1931.387 \mathrm{p}$.

12. Kruisinga E.A. Handbook of Present-Day English. P. II. Groningen, P. Noordhoff, 1931. 508 p.

13. Quirk R.A. Comprehensive Grammar of the English Language. London, Longman, 1985. 1779 p.

14. Sinclair J. Collins CoBUILT English Grammar. London, Collins CoBUILT, 1990. 448 p.

15. Yule G. Explaining English grammar. Oxford, Oxford University Press, 1998. 352 p.

\section{SOURCES}

Fry S. The Liar. London, Soho Press, 1994. 280 p.

\section{Information About the Author}

Olga V. Larina, Candidate of Sciences (Philology), Associate Professor, Department of English Language no. 8, Moscow State Institute of International Relations (MGIMO), Prosp. Vernadskogo, 76, 119454 Moscow, Russian Federation, larinzacho@yandex.ru, olga21.06larin1a@gmail.com.

\section{Информация об авторе}

Ольга Всеволодовна Ларина, кандидат филологических наук, доцент кафедры английского языка № 8, Московский государственный институт международных отношений (Университет), просп. Вернадского, 76, 119454 г. Москва, Российская Федерация, larinzacho@yandex.ru, olga21.06larin1a@gmail.com. 